\title{
Smoking Knowledge, Attitudes, Behavior, and Associated Factors Among Chinese Male Surgeons
}

\author{
Tingting Yao $\cdot$ Michael Ong $\cdot$ Anita Lee \\ Yuan Jiang $\cdot$ Zhengzhong Mao
}

Published online: 14 February 2009

(c) The Author(s) 2009. This article is published with open access at Springerlink.com

\begin{abstract}
Background The purpose of this study was to understand and assess the smoking knowledge, attitudes, behavior, and associated factors among Chinese male surgeons.

Methods A total of 823 Chinese male surgeons from six cities in China participated in a survey of smoking knowledge, attitudes, and behaviors in 2004. This study presents descriptive statistics and logistic regression analyses of factors associated with the respondents' smoking behavior and smoking cessation activity.

Results The current smoking prevalence for Chinese male surgeons was 45.2 , and $42.5 \%$ of respondents reported having smoked in front of their patients. Few of the respondents always asked patients about their smoking status $(25 \%)$ or advised smokers to quit smoking (27.2\%). Logistic regression models found that current smoking status was significantly associated $(P<0.05)$ with the surgeons' knowledge of the harms of active and passive smoking and their attitudes toward
\end{abstract}

T. Yao $\cdot$ Z. Mao $(\bowtie)$

Huaxi School of Public Health, Sichuan University, Chengdu, 610041 Sichuan, China

e-mail: zzmao666@yahoo.com

T. Yao

e-mail: tingtingyao.cn@gmail.com

M. Ong

Department of Medicine, University of California Los Angeles,

757 Westwood Avenue, Los Angeles, California 90095, USA

A. Lee

Center for International Tobacco Control, Public Health

Institute, Berkeley, USA

Y. Jiang

Chinese Center for Disease Control and Prevention, National

Tobacco Control Office, Beijing, China smoke-free hospitals and health role modeling by physicians. Smoking in front of patients was significantly associated $(P<0.05)$ with the respondents' knowledge of active smoking harms, attitudes toward smoke-free hospitals, and cigarette consumption. The surgeons' smoking cessation activity was significantly associated $(P<0.05)$ with their knowledge about the harms of active smoking, their rates of advising patients to quit smoking, and their knowledge of the harms of passive smoking.

Conclusions Male surgeons have the highest smoking prevalence among Chinese physicians. They should actively participate in tobacco control training and education to improve their knowledge and attitudes toward smoking, which will improve their own smoking behavior and smoking cessation practices. Only by engaging all parts of the health care system, including surgeons, can China make headway against its tobacco epidemic.

\section{Introduction}

China produces one third of the world's tobacco supply and has the largest number of cigarette consumers in the world [1]; consumption was 1.7 trillion cigarettes (one third of the world's total) in 2000 [2]. The smoking prevalence in China also is the highest in the world; in 2002, about 300 million adults (age $\geq 15$ years) were current smokers [3]. Ever-smoking rates among adults were $66.0 \%$ for men and $3.1 \%$ for women [4], and current smoking rates were $58.2 \%$ for men and $2.6 \%$ for women.

A study conducted in China in 2004 surveyed 3,652 Chinese physicians and found that the smoking prevalence was $23 \%$ among all Chinese physicians, $41 \%$ for men and $1 \%$ for women [5]. In particular, surgeons had the highest smoking prevalence of all physicians (48.1\%) [6], a finding 
demonstrated in many other studies [7-12]. However, little information is available about the factors that underlie these findings. Previous studies have reported that cigarette smoking produces guanxi (social relationships) $[13,14]$. A study in 2008 reported that cigarette smoking among Chinese surgeons is a pivotal element in a highly embodied set of organizational practices and ethics [15] and likely limits the development of effective tobacco prevention and control programs. Surgeons can play an important role in tobacco control. They care for many patients with smoking-related illnesses, such as lung cancer and cervical cancer, and they can help prevent or minimize these illnesses by acting as healthy role models by changing their own smoking behavior and altering their smoking cessation practices toward patients. In addition, patient illnesses may be aggravated by exposure to secondhand smoke from surgeons who smoke in front of them. Therefore, the main objectives of this study were to determine the smoking knowledge, attitudes, and behavior of male surgeons in China and to examine whether their smoking behavior and smoking cessation activity were affected by modifiable factors such as their knowledge and attitudes toward smoking.

\section{Methods}

Sample

A survey of male surgeons' knowledge, attitudes, and behavior toward smoking was conducted from July 2004 to October 2004 in six cities in China: Guangzhou, Chengdu, Wuhan, Tianjin, Harbin, and Lanzhou. These cities represent six different regions in China: south, southwest, central, north, northeast, and northwest. In each city, five hospitals were randomly selected within the provincial, city, and district levels. A total of 949 surgeons participated in the survey: $13.3 \%$ of the surgeons were female but only $1.6 \%(n=2)$ of them were current smokers, which is consistent with female smoking rates in China [5, 16]. Consequently, this study focused only on the smoking knowledge, attitudes, and behavior of the 823 male surgeons. When the term "respondents" is used, it refers only to the male surgeons in the study.

\section{Design and procedures}

This study was approved by the Institutional Review Boards of the Chinese Center for Disease Control and Prevention and the University of California, Berkeley. Participants were contacted by telephone and asked to participate in a face-to-face interview and complete a selfadministered questionnaire. The face-to-face interviews were conducted by staff members of the Chinese Center for
Disease Control and Prevention. The questionnaire consisted of four sections with 112 total questions. The first section asked questions about the male surgeons' smoking cessation counseling behavior. The second section asked questions about their smoking and their quitting smoking behavior. The third section contained 52 scaled questions that assessed the surgeons' knowledge about their role in smoking prevention and control, smoking-related and passive smoking-related diseases, and methods of smoking cessation. The fourth section contained six demographic questions (age, years of practice, education, position, number of patients per day, and monthly income). To ensure the quality of data collection, $10 \%$ of the questionnaires were examined by a quality control team in each city every day.

\section{Statistical analysis}

All analyses were conducted with STATA, version 9.0 (Stata Corporation, College Station TX, 2003). A descriptive analysis was performed for demographic features (Table 1). Differences in proportion were assessed by the Pearson chi-square test (Table 2). Previous studies have shown that lack of knowledge and inappropriate attitudes toward smoking can influence physicians' smoking behavior $[17,18]$, but these studies were not conducted specifically with Chinese male surgeons. The present study used three logistic regression models to analyze factors related to the participating Chinese male surgeons' smoking status, smoking behavior in front of patients, and smoking cessation activity (Tables 3-5). Odds ratios (OR) and the corresponding $95 \%$ confidence intervals (CI) were computed to assess the strength of association. For the logistic regression analyses, the respondents' smoking status and smoking behavior among current smokers were dichotomized into current smokers (daily smokers and occasional smokers) and nonsmokers (past smokers and never smokers), and into smoking and not smoking in front of patients, respectively. Smoking cessation activity was also dichotomized into (1) always (always or often) and not always (sometimes or rarely or never) asks if a patient smokes, and (2) always (always or often) and not always (sometimes or rarely or never) advises smokers to quit smoking. Analyses accounted for clustering at the city and type of hospital.

This study focused on four groups of explanatory variables in the logistic regression models: (1) professional background, which includes the surgeons' years of practice, education, position, and city; (2) knowledge about the relationship between active smoking and health, and between passive smoking and lung cancer; (3) attitudes regarding whether "health professionals should serve as role models for patients" and "all indoor smoking in hospitals should be prohibited"; and (4) smoking behavior, 
Table 1 Demographic characteristics of male surgeons in China $(n=823)$

\begin{tabular}{|c|c|c|c|c|}
\hline Characteristic & $\begin{array}{l}\text { Total } \\
\%(n=823)\end{array}$ & $\begin{array}{l}\text { Current smoker } \\
\%(n=372)\end{array}$ & $\begin{array}{l}\text { Non smoker } \\
\%(n=451)\end{array}$ & $\mathrm{P}$ value \\
\hline Age & & & & .000 \\
\hline $20-29$ & $27.0(221)$ & $18.3(68)$ & $34.2(153)$ & \\
\hline $30-39$ & 34.9 (286) & $37.1(138)$ & $33.1(148)$ & \\
\hline $40-49$ & $19.8(162)$ & $23.7(88)$ & $16.6(74)$ & \\
\hline $50-69$ & $18.3(150)$ & $21.0(78)$ & $16.1(72)$ & \\
\hline Years of practice & & & & .000 \\
\hline$<10$ years & $40.8(335)$ & $29.0(108)$ & $50.4(227)$ & \\
\hline$\geq 10$ years & $59.2(487)$ & $71.0(264)$ & $49.6(223)$ & \\
\hline Education & & & & .001 \\
\hline$\leq$ College & $18.7(154)$ & $23.7(88)$ & $14.6(66)$ & \\
\hline Bachelor & $68.2(561)$ & $66.1(246)$ & $69.8(315)$ & \\
\hline Master/MD & $13.1(108)$ & $10.2(38)$ & $15.5(70)$ & \\
\hline Position & & & & .000 \\
\hline$\leq$ Junior & $32.5(267)$ & $23.1(86)$ & $40.2(181)$ & \\
\hline Middle-career & 33.7 (277) & $35.5(132)$ & $32.2(145)$ & \\
\hline Associate and senior & $33.8(278)$ & $41.4(154)$ & $27.6(124)$ & \\
\hline City & & & & .000 \\
\hline Guangzhou & $19.3(159)$ & $12.6(47)$ & $24.8(112)$ & \\
\hline Chengdu & $17.6(145)$ & $15.9(59)$ & $19.1(86)$ & \\
\hline Wuhan & $19.4(160)$ & $20.4(76)$ & $18.6(84)$ & \\
\hline Tianjin & $12.9(106)$ & $15.3(57)$ & $10.9(49)$ & \\
\hline Harbin & 13.7 (113) & $14.0(52)$ & $13.5(61)$ & \\
\hline Lanzhou & $17.0(140)$ & $21.8(81)$ & $13.1(59)$ & \\
\hline \multicolumn{5}{|l|}{ Cigarettes smoked per day } \\
\hline$\leq$ half pack & $(195)$ & 52.4 & 0.0 & \\
\hline$>$ half pack & $(177)$ & 47.6 & 0.0 & \\
\hline
\end{tabular}

measured both as smoking in front of patients and the number of cigarettes smoked per day. The key variables of interest are in the last three groups, as they are more modifiable than demographic characteristics. The knowledge variables previously had been shown to differ significantly between physician smokers and nonsmokers but had not been analyzed for their effect on smoking cessation practices [5]. Responses related to knowledge and attitudes were grouped into "agree (related)" and "probably or not agree (probably related, not related, unknown)" and "oppose (strongly oppose, oppose, neutral)" and "support (supportive, strongly supportive)," respectively. A $P$ value of $<0.05$ was considered statistically significant, with all $P$ values being two-tailed.

\section{Results}

Demographic data

Table 1 shows the demographic data for the 823 male surgeons participating in this study. Their mean age was
38 years, and $59.2 \%(n=487)$ had worked more than 10 years. Most $(n=669 ; 81.3 \%)$ had at least a bachelor's medical degree, and $33.8 \%(n=278)$ held an associate or senior position. Among all of the respondents, $19.3 \%$ were from Guangzhou, $17.6 \%$ from Chengdu, $19.4 \%$ from Wuhan, $12.9 \%$ from Tianjin, 13.7\% from Harbin, and 17\% from Lanzhou. The chi-square analysis indicates that significant differences in smoking status were found between subgroups of age, years of practice, education, position, and city.

\section{Smoking prevalence}

The current smoking prevalence for the Chinese male surgeons in the study was $45.2 \%(n=372)$.

The smoking prevalence was highest $(37.1 \%)$ in the middle age group (30-39 years), with lower rates among younger and older surgeons. Among current smokers, over half $(52.4 \%)$ smoked less than half a pack of cigarettes daily, and the average number of years smoked was about 14 years. The three most commonly reported reasons for smoking were stated as (1) smoking makes me feel relaxed; 
Table 2 Male surgeons' knowledge and attitudes toward smoking and passive smoking
${ }^{a}$ Significant $(P<0.05)$ difference between current smoker and nonsmoker

b Significant $(P<0.05)$ difference between smoking and not smoking in front of patients

\begin{tabular}{|c|c|c|c|c|}
\hline & \multicolumn{2}{|l|}{ All $(n=823)$} & \multicolumn{2}{|c|}{ Current smoker $(n=372)$} \\
\hline & $\begin{array}{l}\text { Current smoker } \\
(n=372) \%\end{array}$ & $\begin{array}{l}\text { Non smoker } \\
(n=451) \%\end{array}$ & $\begin{array}{l}\text { Smoking in front of } \\
\text { patients }(n=158) \%\end{array}$ & $\begin{array}{l}\text { Not smoking in front of } \\
\text { patients }(n=214) \%\end{array}$ \\
\hline \multicolumn{5}{|l|}{ Knowledge } \\
\hline \multicolumn{5}{|c|}{ Smoking is harmful to your health ${ }^{\mathrm{a}, \mathrm{b}}$} \\
\hline Agree & 49.7 & 70.7 & 42.7 & 55.1 \\
\hline $\begin{array}{r}\text { Probably or } \\
\text { not agree }\end{array}$ & 50.3 & 29.3 & 57.3 & 44.9 \\
\hline \multicolumn{5}{|c|}{ Passive smoking is related to lung cancer ${ }^{\mathrm{a}}$} \\
\hline Agree & 82.3 & 89.8 & 81.5 & 82.7 \\
\hline $\begin{array}{l}\text { Probably } \\
\text { or not agree }\end{array}$ & 17.7 & 10.2 & 18.5 & 17.3 \\
\hline \multicolumn{5}{|l|}{ Attitudes } \\
\hline \multicolumn{5}{|c|}{ Health professionals should serve as role models for patients ${ }^{a}$} \\
\hline Support & 73.7 & 87.1 & 71.0 & 76.1 \\
\hline Oppose & 26.3 & 12.9 & 29.0 & 23.9 \\
\hline \multicolumn{5}{|c|}{ All indoor smoking in hospitals should be prohibited ${ }^{\mathrm{a}, \mathrm{b}}$} \\
\hline Support & 68.6 & 86.9 & 61.3 & 74.2 \\
\hline Oppose & 31.4 & 13.1 & 38.7 & 25.8 \\
\hline
\end{tabular}

(2) it is necessary for social activities; and (3) smoking is a habit in my daily life. Of note, $42.5 \%(n=158)$ of the current smokers in the study reported having smoked in front of their patients, and over half $(60.8 \%)$ claimed to have made at least one attempt to quit smoking.

Knowledge and attitudes toward smoking

Table 2 describes the knowledge and attitudes of the male surgeons toward smoking. Current smokers were significantly less likely than nonsmokers to believe that smoking is harmful to health $(49.7 \%$ versus $70.7 \% ; P<0.05)$ and that passive smoking is related to lung cancer $(82.3 \%$ versus $89.8 \%$; $P<0.05$ ). Current smokers also were significantly less likely $(P<0.05)$ than nonsmokers to support the views that (1) health professionals should serve as role models for their patients $(73.7 \%$ versus $87.1 \%$; $P<0.05)$ and (2) all indoor smoking in hospitals should be prohibited $(68.6 \%$ versus $86.9 \% ; P<0.05)$.

Current smokers who had ever smoked in front of patients, compared to those who never had done so, were significantly less likely to believe that smoking is harmful to health $(42.7 \%$ versus $55.1 \% ; P<0.05)$ and that all indoor smoking in hospitals should be prohibited $(61.3 \%$ versus $74.2 \% ; P<0.05)$. Current smokers who had ever smoked in front of patients, compared to those who never had done so, were less likely (although not significantly) to know that passive smoking is related to lung cancer or to believe that health professionals should serve as role models for patients $(81.5 \%$ versus $82.7 \% ; P>0.05$; $71.0 \%$ versus $76.1 \% ; P>0.05)$.
Smoking behavior and associated factors

Smoking status (Table 3) was significantly associated $(P<0.05)$ with the respondents' professional background (education, position, city), and also with their knowledge and attitudes toward smoking. Male surgeons who did not agree that active smoking is harmful to one's health $(\mathrm{OR}=2.48)$ or that passive smoking is related to lung cancer $(\mathrm{OR}=2.01)$ were more likely to smoke than those who agreed with these statements. Male surgeons who did not agree that health professionals should serve as role models for their patients $(\mathrm{OR}=1.74)$ or that indoor smoking in hospitals should be prohibited $(\mathrm{OR}=3.09)$ were more likely to smoke than those who agreed with the respective statements.

This study found that professional background (years of practice), knowledge, and attitudes toward smoking, as well as smoking intensity, were significant predictors $(P<0.05)$ of having ever smoked in front of patients (Table 4). Male surgeon smokers who had practiced more than ten years were more likely to have smoked in front of patients. Male surgeons who did not completely agree that smoking is harmful to health were more likely $(\mathrm{OR}=1.64)$ to have smoked in front of patients than those who completely agreed. Male surgeons who did not believe hospitals should be completely smoke-free were more likely $(\mathrm{OR}=1.81)$ to have smoked in front of patients than those who believed that hospitals should be completely smoke-free. Male surgeons who smoked more than a half pack of cigarettes daily were more likely $(\mathrm{OR}=2.67)$ to have smoked in front of patients than those who smoked a half pack or less of 
Table 3 Logistic regression of factors associated with male surgeons' smoking status $(n=823)$

\begin{tabular}{llll}
\hline & Coefficient & OR & $95 \%$ CI \\
\hline $\begin{array}{l}\text { Professional background } \\
\text { Years of practice }\end{array}$ & & & \\
$\quad<10$ years & & Reference & \\
$\quad \geq 10$ years & 0.35 & 1.41 & $0.84-2.39$ \\
Education & & & \\
$\quad \leq$ College & & Reference & \\
Bachelor & -0.50 & $0.61^{*}$ & $0.40-0.94$ \\
$\quad$ Master/MD & -0.88 & $0.42^{* *}$ & $0.23-0.77$ \\
Position & & & \\
$\quad \leq$ Junior & & Reference & \\
Middle-career & 0.57 & $1.77^{*}$ & $1.08-2.91$ \\
$\quad$ Associate and senior & 0.87 & $2.38^{* *}$ & $1.26-4.48$ \\
City & & & \\
$\quad$ Guangzhou & & Reference & \\
Chengdu & & $2.12^{* *}$ & $1.23-3.66$ \\
Wuhan & 0.75 & $2.56^{* *}$ & $1.50-4.37$ \\
Tianjin & 0.94 & $4.04^{* *}$ & $2.23-7.33$ \\
Harbin & 1.40 & $2.92^{* *}$ & $1.62-5.25$ \\
Lanzhou & 1.07 & $6.08^{* *}$ & $3.46-10.69$
\end{tabular}

Knowledge

Smoking is harmful to your health

\begin{tabular}{llll} 
Agree & \multicolumn{3}{c}{ Reference } \\
Probably or not agree & 0.91 & $2.48^{* *}$ & $1.80-3.44$
\end{tabular}

Passive smoking is related to lung cancer

Agree

Reference

$1.25-3.22$

Attitudes

Health professional should serve as role models for patients

\begin{tabular}{llll} 
Support & \multicolumn{3}{c}{ Reference } \\
Oppose & 0.55 & $1.74 *$ & $1.09-2.77$
\end{tabular}

All indoor smoking in hospitals should be prohibited

Support Reference

$\begin{array}{llll}\text { Oppose } & 1.13 & 3.09^{* *} & 1.97-4.84\end{array}$

Constant $\quad-2.21$

$\chi^{2}=184.246 ; \mathrm{df}=14 ; P<0.000$

$* P<0.05$ (2-tailed)

$* * P<0.01$ (2-tailed)

Note: The first category in all variables was regarded as the reference category

cigarettes daily. Knowledge about smoking harms and attitudes about role modeling were not significant predictors of having ever smoked in front of patients.

Smoking cessation activity

In this study, only $25 \%$ of the participating Chinese male surgeons always asked patients about their smoking status.
Table 4 Logistic regression of factors associated with male surgeons' smoking in front of patients $(n=372)$

\begin{tabular}{llll}
\hline & Coefficient & OR & $95 \%$ CI \\
\hline $\begin{array}{l}\text { Professional background } \\
\text { Years of practice }\end{array}$ & & & \\
$\quad<10$ years & & Reference & \\
$\quad \geq 10$ years & 0.71 & $2.04 *$ & $1.09-3.83$ \\
Education & & & \\
$\quad$ College & & Reference & \\
$\quad$ Bachelor & -0.29 & 0.75 & $0.43-1.33$ \\
$\quad$ Master/MD & -0.64 & 0.53 & $0.22-1.28$
\end{tabular}

Position

$\leq$ Middle-career

Reference

$\begin{array}{lll}\text { Associate and senior } & 0.33 & 1.39\end{array}$

$0.79-2.43$

Amount of cigarette smoked per day

$\leq$ half pack

Reference

$>$ half pack

0.98

$2.67 * *$

$1.70-4.20$

Knowledge

Smoking is harmful to your health

Agree

Reference

Probably or not agree $\quad 0.49 \quad 1.64 *$

$1.04-2.57$

Passive smoking is related to lung cancer

$\begin{array}{lll}\text { Agree } & & \text { Reference } \\ \text { Probably or not agree } & 0.05 & 1.05\end{array}$

$0.58-1.91$

Attitudes

Health professional should serve as role models for patients

\begin{tabular}{llll} 
Support & \multicolumn{3}{c}{ Reference } \\
Oppose & 0.02 & 1.02 & $0.57-1.84$
\end{tabular}

All indoor smoking in hospitals should be prohibited

Support Reference

$\begin{array}{llll}\text { Oppose } & 0.60 & 1.81^{*} & 1.05-3.12\end{array}$

Constant $\quad-1.68$

$\chi^{2}=52.339 ; \mathrm{df}=9 ; P<0.000$

$* P<0.05$ (2-tailed)

** $P<0.01$ (2-tailed)

Note: The first category in all variables was regarded as the reference category

Among those surgeons who never or seldom asked their patients about smoking status, the main reason given for not asking was "patient's condition is not related to smoking" (45.3\%). In addition, only $27 \%$ of the male surgeons always advised their patients to quit smoking. Among those respondents who never or seldom advised their patients to quit, the main reason given was the belief that "they could not influence a patient" (39.4\%).

This study found (Table 5) that the male surgeons' "ask" behavior was significantly associated $(P<0.05)$ with their professional background (education, position, city) and their knowledge about smoking. Those who completely agreed with the statement "smoking is harmful 
Table 5 Logistic regression of factors associated with male surgeons' smoking cessation activity $(n=823)$

\begin{tabular}{|c|c|c|c|c|}
\hline & \multicolumn{2}{|c|}{ Always asked if a patient smokes ${ }^{\mathrm{a}}$} & \multicolumn{2}{|c|}{ Always advised smokers to quit ${ }^{\mathrm{b}}$} \\
\hline & Coefficient & OR $(95 \% \mathrm{CI})$ & Coefficient & OR $(95 \% \mathrm{CI})$ \\
\hline \multicolumn{5}{|l|}{ Professional background } \\
\hline \multicolumn{5}{|l|}{ Years of practice } \\
\hline$<10$ years & & Reference & & Reference \\
\hline$\geq 10$ years & -0.29 & $0.75(0.41-1.36)$ & -0.03 & $0.97(0.54-1.75)$ \\
\hline \multicolumn{5}{|l|}{ Education } \\
\hline$\leq$ College & & Reference & & Reference \\
\hline Bachelor & 0.92 & $2.52 *(1.48-4.30)$ & 0.46 & $1.58(0.96-2.62)$ \\
\hline Master/MD & 0.44 & $1.56(0.75-3.22)$ & 0.40 & $1.50(0.76-2.94)$ \\
\hline \multicolumn{5}{|l|}{ Position } \\
\hline$\leq$ Junior & & Reference & & Reference \\
\hline Middle-career & -0.56 & $0.57 *(0.34-0.96)$ & -0.39 & $0.68(0.40-1.15)$ \\
\hline Associate and senior & -0.20 & $0.82(0.41-1.65)$ & -0.19 & $0.83(0.41-1.65)$ \\
\hline \multicolumn{5}{|l|}{ City } \\
\hline Guangzhou & & Reference & & Reference \\
\hline Chengdu & 0.60 & $1.83 *(1.01-3.33)$ & 0.33 & $1.40(0.79-2.46)$ \\
\hline Wuhan & 0.80 & $2.23 *(1.26-3.95)$ & 0.33 & $1.39(0.79-2.42)$ \\
\hline Tianjin & 0.78 & $2.17 *(1.16-4.09)$ & 0.35 & $1.42(0.78-2.60)$ \\
\hline Harbin & 0.75 & $2.11 *(1.13-3.95)$ & 0.51 & $1.67(0.92-3.02)$ \\
\hline Lanzhou & 0.66 & $1.93 *(1.06-3.52)$ & -0.10 & $0.91(0.50-1.65)$ \\
\hline \multicolumn{5}{|l|}{ Knowledge } \\
\hline \multicolumn{5}{|c|}{ Smoking is harmful to your health } \\
\hline Agree & & Reference & & Reference \\
\hline Probably or not agree & -0.38 & $0.69 *(0.48-0.98)$ & -0.39 & $0.68 *(0.47-0.97)$ \\
\hline \multicolumn{5}{|c|}{ Passive smoking is related to lung cancer } \\
\hline Agree & & Reference & & Reference \\
\hline Probably or not agree & -0.50 & $0.95(0.58-1.57)$ & -0.60 & $0.55 *(0.32-0.96)$ \\
\hline \multicolumn{5}{|l|}{ Attitudes } \\
\hline \multicolumn{5}{|c|}{ Health professional should serve as role models for patients } \\
\hline Support & & Reference & & Reference \\
\hline Oppose & 0.47 & $1.60(0.99-2.59)$ & 0.16 & $1.18(0.71-1.95)$ \\
\hline \multicolumn{5}{|c|}{ All indoor smoking in hospitals should be prohibited } \\
\hline Support & & Reference & & Reference \\
\hline Oppose & -0.21 & $0.81(0.50-1.31)$ & -0.49 & $0.61(0.37-1.02)$ \\
\hline Constant & -1.92 & & -1.10 & \\
\hline
\end{tabular}

a $\chi^{2}=56.94 ; \mathrm{df}=14 ; P<0.000$

b $\chi^{2}=29.16 ; \mathrm{df}=14 ; P<0.000$

$* P<0.05$ (2-tailed)

** $P<0.01$ (2-tailed)

Note: The first category in all variables was regarded as the reference category

to health" were 1.45 times more likely $(\mathrm{OR}=0.69)$ to always ask if a patient smokes than those who did not completely agree with this statement. Knowledge that passive smoking is related to lung cancer and attitudes about role modeling and smoking bans in hospitals were not significantly associated with the male surgeons' "ask" behavior.
The respondents' "advise" behavior was significantly associated $(P<0.05)$ with their knowledge. Those who completely agreed that smoking is harmful to health and that passive smoking is related to lung cancer were 1.47 times $(\mathrm{OR}=0.68)$ and 1.82 times $(\mathrm{OR}=0.55)$, respectively, more likely to always advise smokers to quit than those who did not completely agree with these statements. 
Attitudes about role modeling and smoking bans in hospitals were not significant predictors of the male surgeons' "advise" behavior.

\section{Discussion}

This study focused on the smoking knowledge, attitudes, and behavior of Chinese male surgeons and examined how their knowledge and attitudes affect their smoking behavior and smoking cessation activity.

The Chinese male surgeons in the study had the highest smoking prevalence $(45.2 \%)$ of all physicians, which potentially means a higher death rate among surgeons. A study of 34,439 British male doctors showed that those who continued to smoke cigarettes lost, on average, about 10 years of life compared with nonsmokers [19]. The Chinese government invests a great deal in the development of health care professionals, from medical school education to hospital training; high death rates among physicians caused by smoking-related diseases represent a huge loss to society. In addition, physicians are among the most influential role models to the general population. The high smoking prevalence among Chinese male surgeons provides an unhealthy role model for patients. Thus, it is necessary to take effective measures to reduce the smoking prevalence among male surgeons in China.

Education is important to improve male surgeons' knowledge and attitudes toward smoking. Previous research has shown that surgeons have a much lower quitting rate and lower scores on knowledge and attitudes toward smoking than internists [6]. The present study suggests that improving male surgeons' knowledge and attitudes toward smoking will have a significant impact on their smoking status, their smoking behavior in front of patients, and their smoking cessation activity. There are two feasible ways to educate male surgeons: (1) implement continuous education and training for current male surgeons on smoking harms and cessation effectiveness, through such methods as health education lectures and smoke-free brochures; (2) add appropriate content and practice on tobacco-related matters, from smoking prevention to cessation and policy, into the medical school curricula for future male surgeons.

Health professionals should have confidence in the impact of smoking cessation practices. This study found that many of the respondents perceived that their smoking cessation advice would not have an effect on patients. However, smoking cessation activities by male surgeons can have a significant positive impact on quitting by patients. According to previous studies, a patient's desire to quit smoking is correlated with a doctor's advice to quit
[20]. Another study showed that $40 \%$ of smokers attempted to quit in response to a doctor's advice [21]. A metaanalysis of 26,000 smokers also confirmed that very brief advice from a physician would significantly increase the rate of quitting smoking among patients [22, 23]. Therefore, it should be the goal of every physician to always ask their patients if they smoke, advise smokers to quit, and use recommended strategies that take only a short time to perform [24]. Doing so would have a huge influence on reducing Chinese smoking rates.

Although many hospitals in China have already nominally implemented smoke-free policies, the high rate of smoking in front of patients shows that it is necessary to strengthen these policies. A major barrier to the implementation of smoke-free policies in Chinese hospitals is the common practice of patients' relatives proffering cigarettes to doctors [15]. It has also been reported that smoking behavior by the director and other senior members of the ward hospital staff influences smoking behavior by junior surgeons [25]. Education of surgeons, who have the highest rate of smoking among Chinese physicians, combined with a media campaign about the importance of smoke-free policies to influence the public, could help strengthen smoke-free policies in hospitals. Smoke-free hospitals could not only reduce smoking activity and improve patient health, but they also could protect nonsmokers from passive smoking.

A limitation of this study is that it relies on selfreported smoking behavior. It is possible that social desirability may result in bias in our estimates of male surgeons' attitudes and behavior concerning smoking cessation activities. Further, this study also did not examine male surgeons in rural areas, where $60 \%$ of the Chinese population resides.

In conclusion, this study shows a high smoking prevalence among male surgeons in China. Male surgeons should actively participate in tobacco control training and education to improve their knowledge and attitudes toward smoking. Doing so will lead to improvements in surgeons' own smoking behavior, as well as their asking about patient smoking status on a routine basis and encouraging smokers to quit. Only by engaging all parts of the health care system, which includes surgeons, can China make headway against its tobacco epidemic.

Acknowledgments The authors thank Professor Teh-wei Hu of the University of California, Berkeley, for his comments on the manuscript. This study was supported by the U.S. National Institutes of Health, Fogarty International Center (grant R01 TW05938).

Open Access This article is distributed under the terms of the Creative Commons Attribution Noncommercial License which permits any noncommercial use, distribution, and reproduction in any medium, provided the original author(s) and source are credited. 


\section{References}

1. Mackay J, Eriksen M (2002) The Tobacco Atlas. Geneva, WHO

2. Hu T, Mao Z, Jiang $\mathrm{H}$ et al (2007) The role of government in tobacco leaf production in China: national and local interventions. Int J Public Policy 2:235-248

3. Yang G, Ma J, Liu N et al (2005) Smoking and passive smoking in China, 2002. Zhonghua Liu Xing Bing Xue Za Zhi 26:77-83 (in Chinese)

4. Sung H, Wang L, Jin S et al (2006) Economic burden of smoking in China, 2000. Tobacco Control 15(Suppl I):i5-i11

5. Jiang Y, Ong M, Tong E et al (2007) Chinese physicians and their smoking knowledge, attitudes and practices. Am J Prev Med 33:15-22

6. Jiang Y, Wei X, Tao J et al (2005) Chinese physician smoking status in six cities. China Health Education 21:403-407

7. Sotiropoulos A, Gikas A, Spanou E et al (2007) Smoking habits and associated factors among Greek physicians. Public Health 121:333-340

8. Bolinde G, Himmelmann L, Johansson K (2002) Swedish physicians smoke least in all the world. A new study of smoking habits and attitudes to tobacco. Lakartidningen 99:3111-3117

9. Aasland O, Nylenna M (1997) Physicians who smoke. A survey of smoking habits and life style of Norwegian physicians. Tidsskr Nor Laegeforen 117:332-337

10. Widimsky J, Skibova J, Skodova Z et al (1992) Smoking habits of male and female physicians in the Czech Republic. Vnitr Lek 38:1208-1214

11. Samuels N (1997) Smoking among hospital doctors in Israel and their attitudes regarding anti-smoking legislation. Public Health 111:285-288

12. Polyzos A, Gennatas C, Veslemes M et al (1995) The smokingcessation promotion practices of physician smokers in Greece. $\mathrm{J}$ Cancer Educ 10:78-81

13. Walder A (1986) Communist neo-traditionalism: work and authority in Chinese industry. University of California Press, Berkeley, CA
14. Charles S (1994) Gifts, favors, and banquets: the art of social relationships in China. Cornell University Press, Ithaca, NY

15. Kohrman M (2008) Smoking among doctors: governmentality, embodiment, and the diversion of blame in contemporary China. Med Anthropol 27:9-42

16. Li H, Fish D, Zhou X (1999) Increase in cigarette smoking and decline of anti-smoking counselling among Chinese physicians: 1987-1996. Health Promot Int 14:123-131

17. Young M, Ward J (1998) Improving smoking cessation advice in Australian general practice: what do GPs suggest is needed? Aust N Z J Public Health 22:777-780

18. Abdullah A, Husten C (2004) Promotion of smoking cessation in developing countries: a framework for urgent public health interventions. Thorax 59:623-630

19. Doll R, Peto R, Boreham J et al (2004) Mortality in relation to smoking: 50 years' observations on male British doctors. Br Med J 328:1519

20. Eckert T, Funker C (2001) Motivation for smoking cessation: what role do doctors play? Swiss Med Wkly 131:521-526

21. Kreuter M, Chheda S, Bull F (2000) How does physician advice influence patient behaviour? Evidence for a priming effect. Arch Fam Med 9:426-433

22. Lancaster T, Stead L, Silagy C et al (2000) Effectiveness of interventions to help people stop smoking: findings from the Cochrane Library. BMJ 321:355-358

23. Kottke TE, Battista RN, DeFriese GH et al (1988) Attributions of successful smoking cessation interventions in medical practice: a meta-analysis of 39 controlled trials. JAMA 259:2882-2889

24. Fiore M, Bailey W, Cohen S (2000). Treating tobacco use and dependence: clinical practice guideline. US Department of Health and Human Services, Public Health Service, Rockville, MD, 2000

25. Editorial (2005) Doctors, please throw away the cigarettes. Health J 5(31) (in Chinese) 